\section{Um estudo sobre a evolução cronológica e intervenções realizadas no convento de Igarassu.}

A study on the chronological evolution and interventions carried out in the lgarassu convent.

\section{Ana Maria Moraes Guzzo*}

*Arquiteta e Urbanista graduada pela Faculdade de Arquitetura e Urbanismo da Universidade Federal do Rio de Janeiro (1991). Mestre em História e Teoria da Arquitetura pelo Programa de Pós-graduação em Arquitetura - PROARQ FAU UFRJ (1999). Doutora do PROARQ FAU UFRJ (2020). Ênfase nos temas: história da arquitetura, arquitetura religiosa. Possui segunda Graduação em Medicina, pela Universidade Estadual do Rio de Janeiro - UERJ (1975), anammguzzo@gmail.com usjt

\section{arq.urb}

número 30 |jan-abr de 2021 Recebido: 03/05/2020 Aceito: $01 / 02 / 2021$

\section{Palavras-chave:}

Arquitetura franciscana

Restauração.

Patrimônio.

\section{Keywords:}

Franciscan architecture.

Restoration.

Patrimony

\section{Resumo}

Este artigo trata das intervenções no Convento Franciscano de Santo Antônio localizado em Igarassu, no estado de Pernambuco (Brasil). Tais intervenções ocorreram a partir de seu tombamento, em 1938, pelo Instituto do Patrimônio Histórico e Artístico Nacional (IPHAN), criado em 1937. Seu objetivo é caracterizar a evolução arquitetônica do Convento de uma maneira análoga a um prontuário médico, além de, analisar as intervenções documentadas sob a ótica das teorias da restauração, contextualizadas à época de suas execuções. A pesquisa se baseou na revisão bibliográfica de autores consagrados da teoria da restauração e em documentação textual e iconográfica disponíveis nos arquivos do IPHAN do Rio de Janeiro e de Pernambuco que, contudo, carecem de registros atualizados sobre os monumentos inscritos na lista de nosso patrimônio. $\mathrm{O}$ estudo foi complementado com informações obtidas em visitas a campo. Dessa forma se elaborou um breve histórico crítico sobre a "vida" desse convento, que auxiliou na construção da trajetória do bem em questão.

\section{Abstract}

This paper deals with the interventions in the Convento Franciscano de Santo Antônio in Igarassu, in the State of Pernambuco (Brazil). Those interventions took place as of its historic heritage listing, in 1938, by the Instituto de Patrimônio Histórico e Artístico Nacional (IPHAN), which was established in 1937. The aim of this work is to characterize the architectural evolution of the Convent in a way analogous to a medical record, as well as to analyze the interventions documented from the viewpoint of the theories of restauration, contextualized at the time they were made. The research was based on the bibliographic revision of he renowned authors of the theories of restauration and on textual and iconographic documentation found in the archives of the IPHAN in Rio de Janeiro and in Pernambuco which, however, lack updated records of the monuments listed in our historic heritage. The study was complemented with information obtained in field trips. Therefore, we developed a brief historical critique about the "life" of this convent, which helped us to design the trajectory of the asset in question. 


\section{Introdução}

O Convento Franciscano de Santo Antônio em Igarassu, pertencente à Província de Santo Antônio, que abrange os cenóbios do Nordeste brasileiro, no estado de Pernambuco (Brasil), foi tombado pelo IPHAN em 1938 e, a partir desta data, suas obras seguiram os critérios estabelecidos pelo órgão oficial de preservação do nosso patrimônio. Contudo, a documentação sobre essas intervenções é falha, embora a arquitetura franciscana presente em território brasileiro ocupe um lugar de destaque em nosso patrimônio cultural, por ser objeto de pesquisa de vários historiadores e por fazer parte do "acervo" do Instituto do Patrimônio Histórico e Artístico Nacional (IPHAN), criado em 1937 sobre a sigla de SPHAN.

O objetivo deste trabalho é, principalmente, caracterizar a evolução arquitetônica cronológica do convento a partir de seu tombamento, além de analisar as intervenções ocorridas nesse processo, em relação ao referencial teórico da restauração da época. Essa arquitetura necessita de registros de documentação e de novos olhares. Ademais, é necessário chamar a atenção para a importância da pesquisa histórica e registro das intervenções ocorridas nos monumentos tombados.

Para isso, a estratégia foi descrever as intervenções de uma maneira análoga a um prontuário médico, no qual as anotações das impressões são de vital importância para longevidade do paciente. Assim, buscando a atualização do "prontuário" e construindo um breve histórico sobre a "vida" dessa edificação, foram realizadas pesquisas arquivísticas nos acervos do IPHAN no Rio de Janeiro e em Recife, que abrangeram documentação textual e iconográfica caracterizadas por ofícios, boletins mensais de informações, inventários e relatos de campanhas de obras, levando-se em conta as ações de maior relevância. Foi feito ainda o registro fotográfico em visitas de campo, de modo a atualizar informações sobre o bem. A pontual análise das intervenções é feita com base em revisão bibliográfica de teóricos da restauração.

${ }^{1}$ A grafia da cidade aparece também como Igaraçu. Neste trabalho será adotada a escrita Igarassu, por apresentar-se desta forma nos documentos arquivísticos do IPHAN.
Um estudo sobre a evolução cronológica e intervenções realizadas no convento de Igarassu.

Esta investigação ajuda a complementar a trajetória do bem em questão, de modo que os dados e análises oriundos desta pesquisa possam direcionar futuras intervenções.

Certo dia...

O Convento de Santo Antônio em Igarassuํ (PE) foi construído no Brasil, em 1588 (ROWER, 1941) atendendo à solicitação do povo.

Por ocasião das invasões holandesas, em 1632, sofreu danos e saques, mas foi ampliado e reconstruído em 1662, quando os invasores já haviam deixado o país (BELO, 2013).

Retratado, em 1665, em uma pintura executada por Franz Post (figura 1), o monumento se mostra como exemplo de um primeiro ciclo dessas construções. De dimensões contidas, com sineira à direita ${ }^{2}$ e afastada da Igreja, possuiu porta única resguardada por um alpendre.

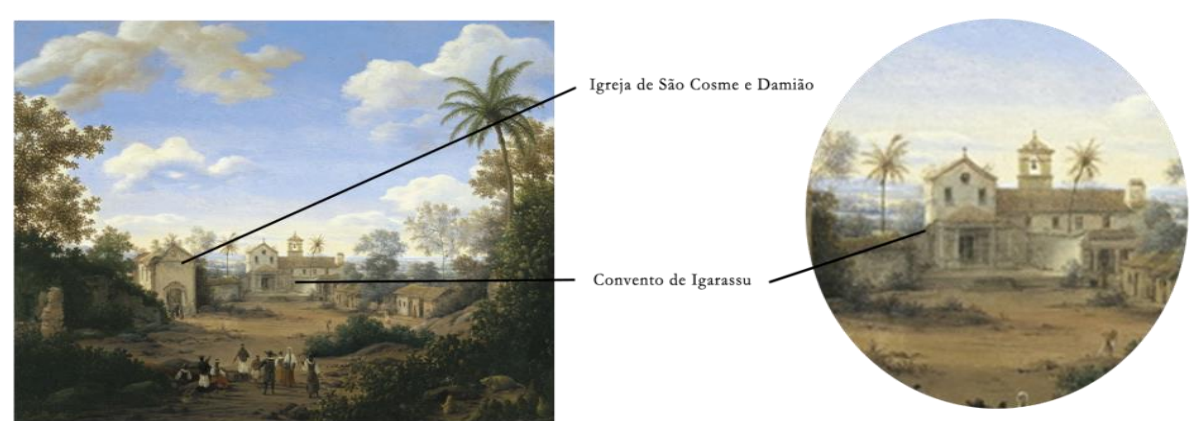

Figura 1: Quadro de Frans Post, 1665. Igreja de São Cosme e Damião à esquerda e Convento de Igarassu ao centro. Fonte: CORRÊA do Lago, Pedro; CORRÊA do Lago, Bia. Frans Post (1612-1680). Obra Completa. Rio de Janeiro, 2006

De acordo com Jaboatão (1858), as obras de acréscimo significativo foram iniciadas somente em 1722. Os trabalhos de decoração continuaram até fins do século XVIII

${ }^{2} \mathrm{O}$ referencial usado para considerarmos os termos direita e esquerda é com o observador do lado de fora, olhando para o complexo conventual. 
(SILVA, 2000). Uma pintura, feita por volta de 1720 (figura 2), existente na Pinacoteca instalada no convento e aberta ao público desde 1957, ilustra o monumento, com torre sineira à direita e amparo do frontão finalizado por duas aletas simples.

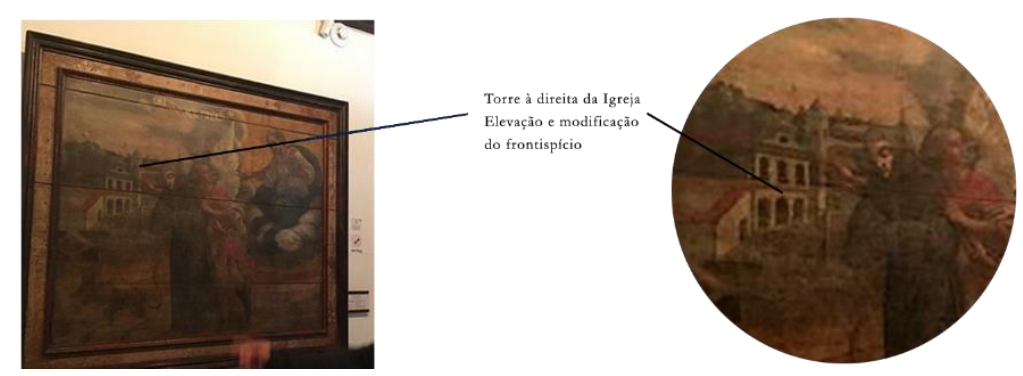

Figura 2: Quadro pintado cerca de 1720. Igreja de São Cosme e Damião à esquerda e Convento de Igarassu ao centro. Disponível em:https://www.tripadivisor.com.br/Attraction_Reviewg2343204-d4376498-Reviews-Pinacoteca_de_Igarassu_museum-Igarassu_State_of_Pernambuco.html

O frontispício da igreja conventual mostra uma galilé com três arcos, onde se assenta o coro. A modificação do frontão com volutas com duplo enrolamento data de 1786, ano gravado na base do cruzeiro.

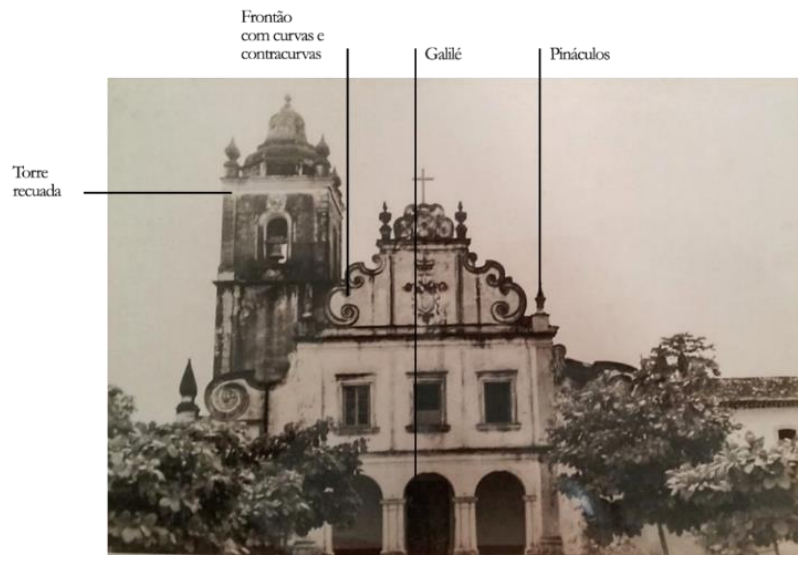

Figura 3: Fachada principal do Convento de Igarassu, década de 1950. Fonte: Pasta Série Inventário, IPHAN/RJ. Cx 310 Pt 02 E06. Foto Eric Hess
Um estudo sobre a evolução cronológica e intervenções realizadas no convento de lgarassu.

A torre se tornou recuada em relação à fachada e localizada no lado esquerdo da igreja conventual, construída cerca de 1753, época em que se começou a edificar a capela da Ordem Terceira, concluída em 1762, em comunicação com a igreja Primeira (BELO, 2013). Uma cerca delimita o espaço do convento, e no adro, vemos o cruzeiro de pedra copiado do original construído em 1786, que sucumbiu durante o século XX. Tais modificações já correspondiam ao segundo ciclo construtivo desses conventos (figura 3 )

O acesso à igreja dos frades faz-se por três portas localizadas na galilé que, na década de 1950, possuía gradis de ferro (BELO, 2013).

A porta do lado direito leva à portaria que se antepõe ao claustro e a da esquerda, guarda um oratório, tendo sido passagem para a capela dos terceiros, que hoje não mais existe (JABOATÃO, 1858).

Esta capela era localizada de maneira perpendicular à nave da igreja conventual (figura 4). Depois de demolida no século XX, a comunicação entre as igrejas foi entaipada e revestida por azulejos retirado da capela-mor da igreja conventual em data não especificada (BELO, 2013).

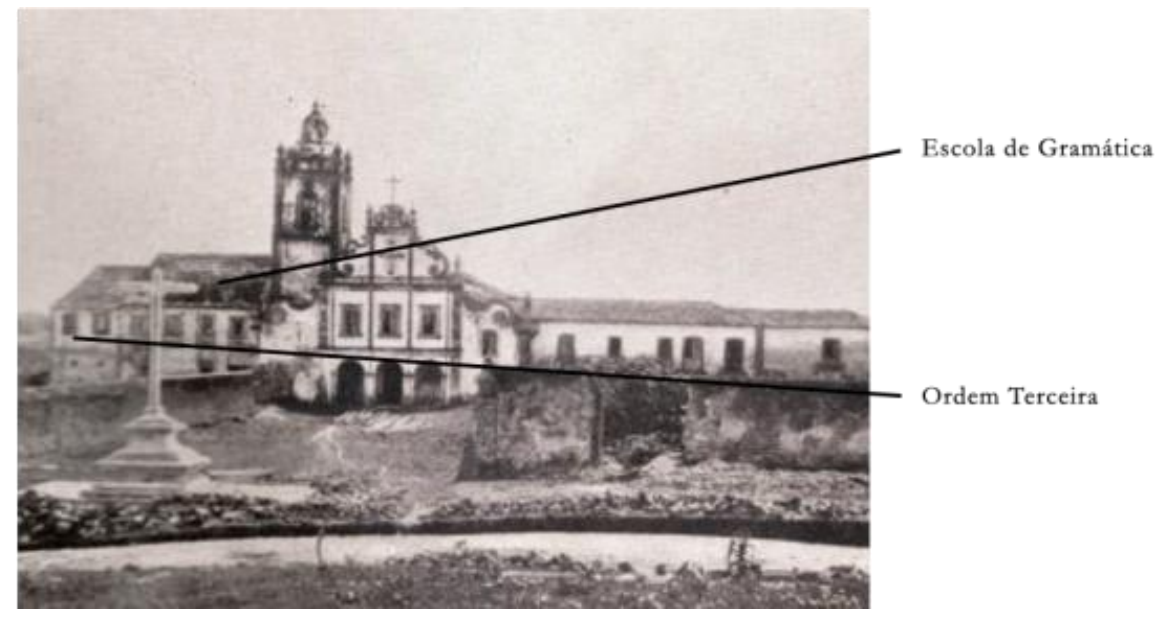

Figura 4: Foto do convento de Igarassu, 1913. Cruzeiro, fachada da igreja com torre recuada; ala conventual à direita; à esquerda, escola de gramática e capela da Ordem Terceira Fonte: Arquivos da FUNDARPE do Recife 
O que ainda se sabe sobre o convento dessa época, é que em 1848 serviu de quartel-general durante a Revolução Praieira, uma revolta de caráter liberal e federalista ocorrida em Pernambuco entre os anos de 1848 e 1850.

Em 2000 foi publicada em Lisboa a obra "Igreja de Santo António de Igarassu- Memória e Futuro - Continuidades Barrocas" que aborda um projeto de restauração de bens integrados realizado na Igreja de Igarassu, em parceria com a Fundação Ricardo Espírito Santo Silva- FRESS (Lisboa), a Fundação Xavier de Sallas (Trujillo), Fundação Joaquim Nabuco (FUNDAJ) e a Fundação Brasil-Portugal entre 1996 e 1998. Nesta obra ressaltou-se que o convento havia sofrido inúmeras "cirurgias" desde o século XVIII, sem a presença de registros (SILVA, 2000). O que hoje conhecemos dessa casa religiosa é produto das obras da segunda metade do século XX.

\section{Após o "Tombo"}

Desde a criação do nosso patrimônio histórico e artístico, a meta era a defesa da legitimidade do conjunto de bens brasileiros. $O$ valor deste conjunto, correspondia ao valor cultural, de um sentimento do "pertencer" a uma comunidade, vinculada a uma identidade nacional, assim justificando sua proteção e preservação.

Dessa forma, os fundadores do IPHAN destacaram o valor histórico dos bens coloniais como mostruários do passado, especialmente os exemplares da arquitetura religiosa dos séculos XVI, XVII e XVIII. Assim surgiu o tombamento dos bens, como meio de sua conservação (FONSECA, 1997) e o conjunto Igreja e Convento de Santo Antônio em Igarassu foi tombado ${ }^{3}$ pelo IPHAN em 17 de maio de 1938, registrado no livro do Tombo das Belas Artes, incluindo o Adro, o Cruzeiro e a área da sua antiga cerca. Ocorreu novo tombamento ${ }^{4}$ no que concerne ao acervo do Convento, conforme a Resolução do Conselho Consultivo da Secretaria do Patrimônio Histórico e Artístico Nacional, de 13 de agosto de 1985.
Um estudo sobre a evolução cronológica e intervenções realizadas no convento de Igarassu.

\section{Prontuário Cirúrgico}

O acervo de documentos dos bens tombados pelo IPHAN está acondicionado em pastas de: plantas, obras e inventários, acrescido da seção de fototeca e mapoteca. Cada pasta contém a documentação textual pertinente às ações desenvolvidas no monumento. Porém, há lacunas relacionadas justamente em relação às próprias intervenções, havendo interrupção de informações. Muitas vezes, os relatos encontrados não são relevantes ao nosso trabalho, de forma que citaremos, do material coletado, o que consideramos como auxiliares para nossa análise e para melhor compreensão por parte do leitor. Os documentos, vistos por nós, como fundamentais para o trabalho que propomos, será merecedor de comentário e inseridos no texto.

O primeiro documento encontrado é datado de 28 de março de 1929, escrito por Annibal Fernandes, e versa sobre o papel de alguns conventos como formadores de núcleos urbanos. Dentre esses conventos, o de Igarassu é citado, bem como o estado de sua edificação, cujo forro da igreja, com pinturas, vinha sendo destruído por cupins, e seus azulejos estavam se desprendendo das paredes úmidas, na iminência de cair. Essa documentação consta da pasta de inventário do convento, no Arquivo do IPHAN/RJ, e é um alerta para a situação da edificação e sobre a sua importância de ser preservada. Não há informações a respeito das providências tomadas nessa ocasião.

Já mencionamos que, no século XX, os azulejos da capela-mor da igreja foram usados para cobrir o arco entaipado de comunicação entre as igrejas dos Terceiros e a conventual, sem que houvesse registro dessa intervenção.

Por meio das lentes do fotógrafo Hess, em 1939, encontramos uma foto do complexo conventual (Figura 5). 


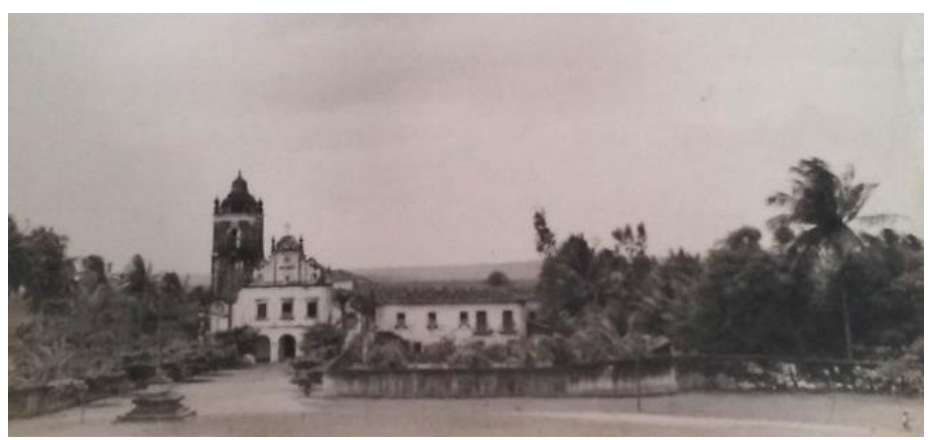

Figura 5: Vista do Convento de Igarassu, 1939. Fonte: Pasta Série Inventário do Convento de Igarassu, IPHAN/RJ. Foto no 17135 , Eric Hess.

Um Ofício datado de 13 de janeiro de 1943 relata acréscimo de terraços e alpendres no convento, através de quatorze fotos. Porém, estas fotografias não foram por nós encontradas.

Saltando no tempo para 24 de abril de 1948, o Ofício de no 55/48, escrito pelo chefe do 10 Distrito do DPHAN, Ayrton Carvalho, destinado ao Diretor Geral, relatava informações sobre reparos urgentes a serem realizados no convento, tais como escoramento de cobertura e retirada de arbustos do frontão. Estas obras foram concluídas em 29 de maio do mesmo ano, conforme Ofício no 66/48, firmado pelas mesmas pessoas.

Em novembro de 1955, assinalamos o Boletim de Informação no 10/55, que menciona: despesas com obras de colocação de andaimes na fachada principal; desmonte de peças de cantaria do tímpano para retirada de arbustos; remoção de reboco da fachada e de três grades de ferro existentes no átrio; remoção de três esquadrias envidraçadas que ocultavam as folhas almofadadas primitivas; e ainda a retirada de cal que encobria a cantaria da fachada (Figura 6).

Ao se extirpar as raízes existentes no frontão, viu-se que, nas vergas das cercaduras de cantaria das janelas, havia tímpanos com volutas, interrompidos, provavelmente com elementos esculpidos. As cercaduras de cantaria das três janelas, apresentavam relevos decompostos em função de serem de pedra calcária. Talvez o desaparecimento dos tímpanos seja resultante também da decomposição. O piso do átrio estava alteado com o revestimento assentado.
Um estudo sobre a evolução cronológica e intervenções realizadas no convento de Igarassu.

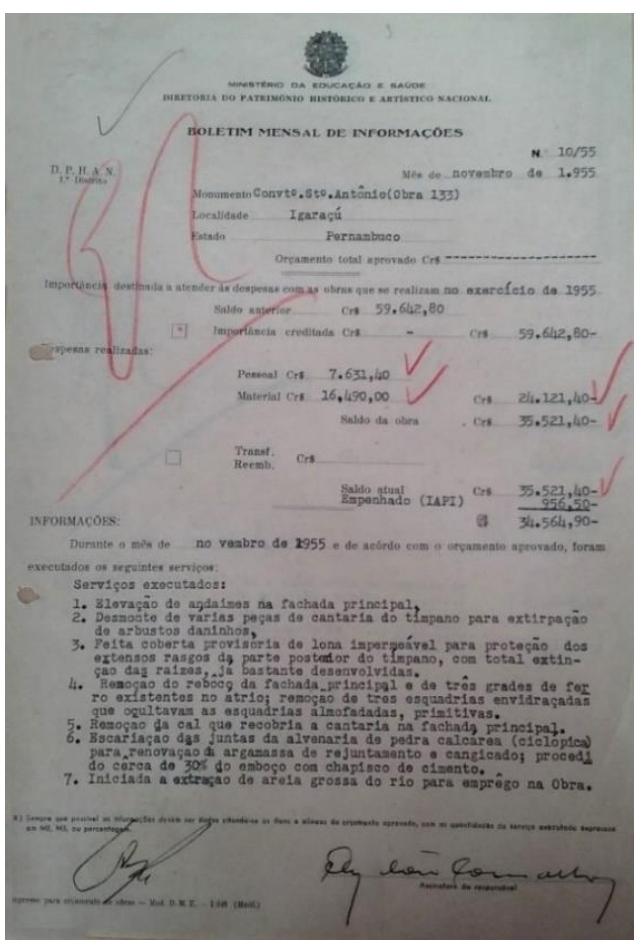

Figura 6: Boletim Mensal de Informação 10/55, novembro de 1955. Fonte: Pasta Série Obras do Convento de Igarassu, IPHAN/RJ.

Na ocasião surgiram dúvidas quanto às tomadas de decisão na obra de restauro:

Refazer as cercaduras em cantaria ou renová-las em massa, mantendo os trechos aproveitáveis? Colocar ou não os tímpanos das janelas? Na fachada lateral esquerda os dois vãos que parecem ter sido colocados em ocasião posterior, devem ser conservados ou fechados? Os coruchéus que ladeiam o tímpano do frontispício são de cantaria e primitivos, enquanto os intermediários e os inferiores são de massa, e de épocas mais recentes; assim, deve-se recompô-los dentro do estilo original? A cruz de cantaria do frontispício desapareceu, e a atual é de madeira. Deve-se substituí-la? É válido remover as esquadrias envidraçadas que escondem as almofadas de madeira, originais? Tais observações foram encontradas em foto e no Ofício18/56 Recife, de 09/02/56, do arquivo central do IPHAN/RJ (Figuras 7 e 8). 


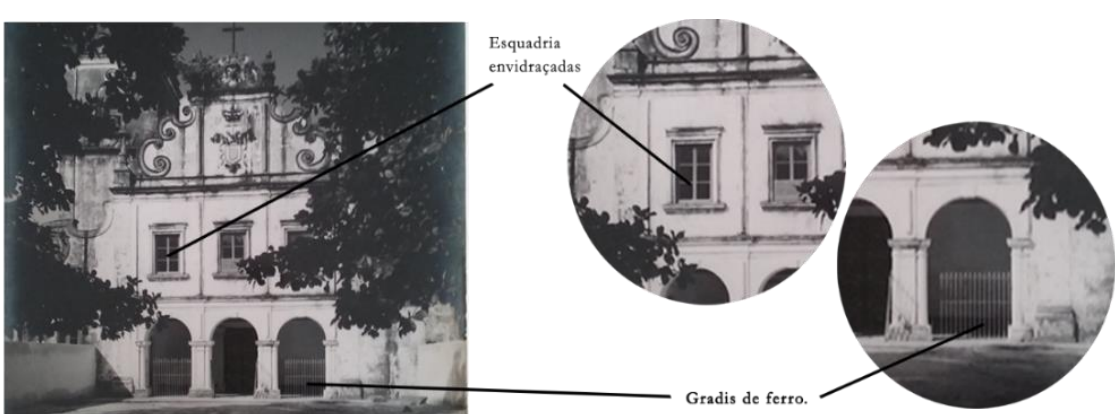

Figura 7: Fachada do convento, 1956. Observar pináculos (ou coruchéus), esquadria de vidro na frente das janelas com folhas de madeira almofadadas e cruz em madeira coroando o frontispício. Janelas sem tímpanos, cercaduras em cantaria. Raízes de arbustos no frontão. Gradis de ferro fechando a galilé. Fonte: Pasta Série Inventário do Convento de Igarassu, IPHAN/RJ. Cx 310; Pt 02: E 05. Foto Marcel Gautherot

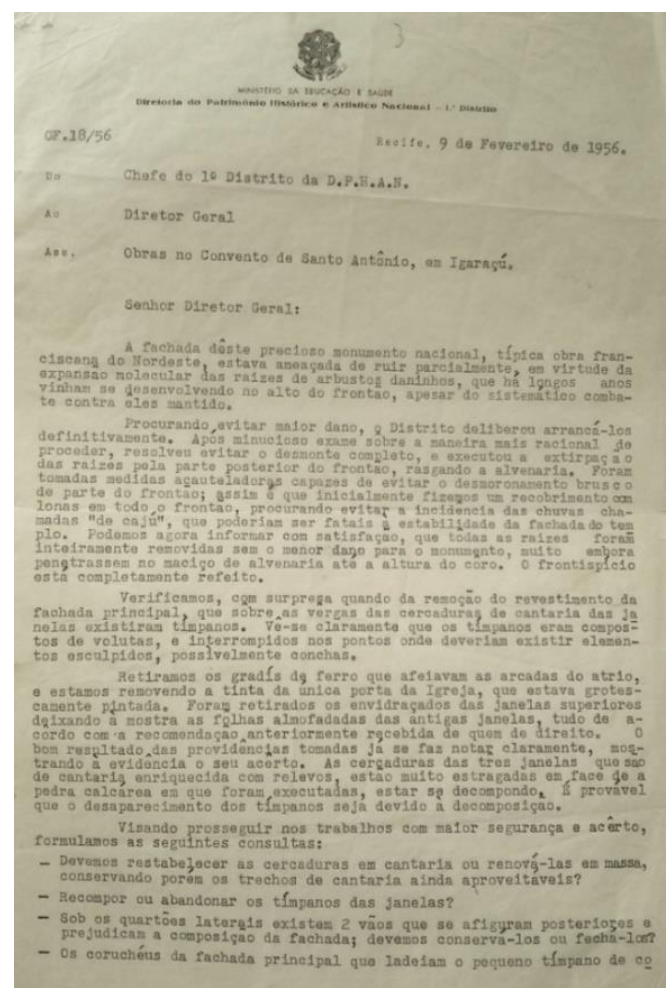

Figura 8: Ofício 18/56
Um estudo sobre a evolução cronológica e intervenções realizadas no convento de lgarassu.

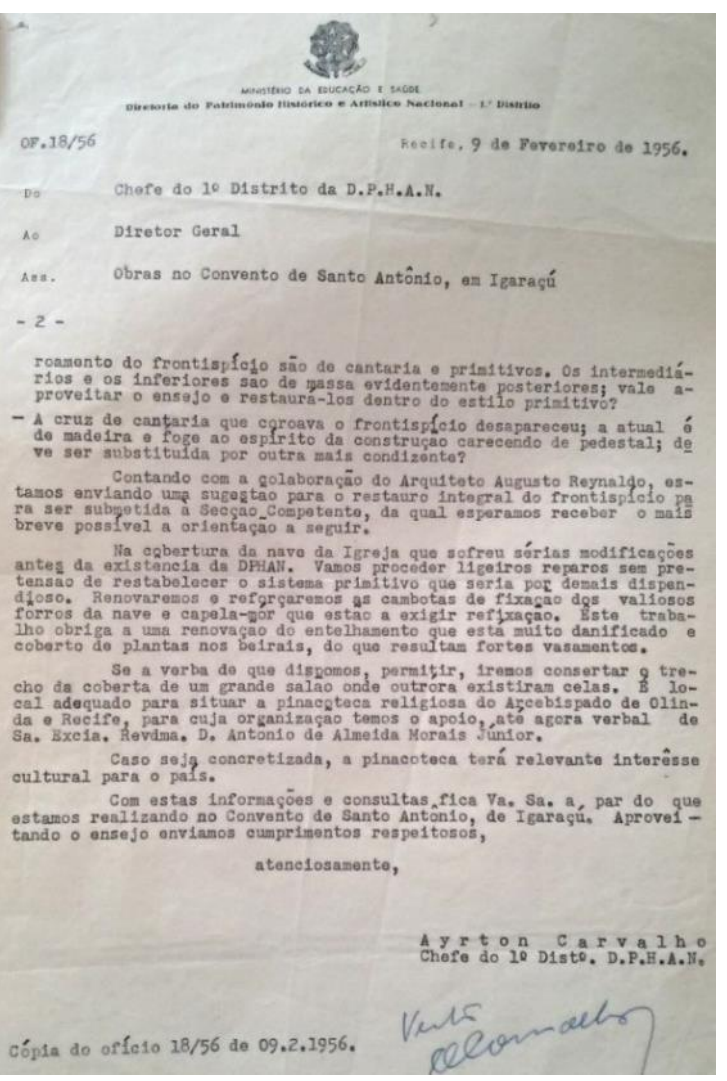

Figura 8: Continuação do Ofício 18/56. Fonte: Pasta Série Obras do Convento de Igarassu, IPHAN/RJ.

Frente às dúvidas, optou-se por retirar os gradis de ferro e os vidros das janelas (1955), refazer a cruz e os pináculos em cantaria (1957), manter as janelas sem tímpano e rebaixar o piso do átrio para liberar os pórticos ali existentes, cujas bases estão soterradas, conforme mostra a figura a seguir (figura 9). 


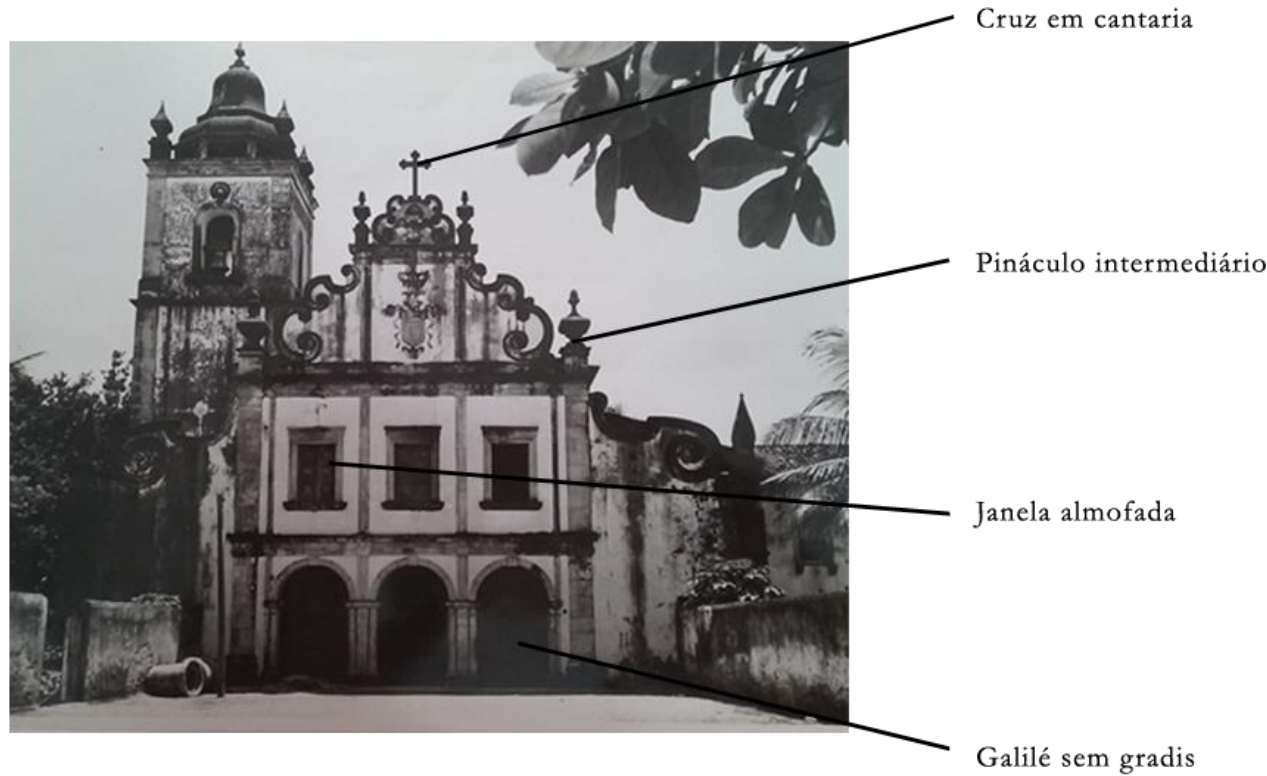

Figura 9: Fachada do Convento de Igarassu com as modificações ocorridas, 1969. Fonte: Pasta Série Inventário IPHAN/RJ. Cx 310; Pt 1215. Foto no 71610, Silva Telles.

Ainda de acordo com o Ofício 112 Recife, de 29/06/56 (figura 10), encontrado no IPHAN/RJ, há referência às seguintes obras: no tocante à nave da Igreja, retirar os "feios vitrais", e modificar a forma dos vãos que os contém, os quais não foram considerados integrados ao ambiente (figura 11). Assim, seteiras tomaram o lugar das antigas janelas (1957) (figura 12). O piso da nave cimentado deveria ser substituído por madeira, que originalmente cobria as campas (figuras 13 e 14). Na mesma altura foi feito o restauro total do frontispício da igreja conventual.

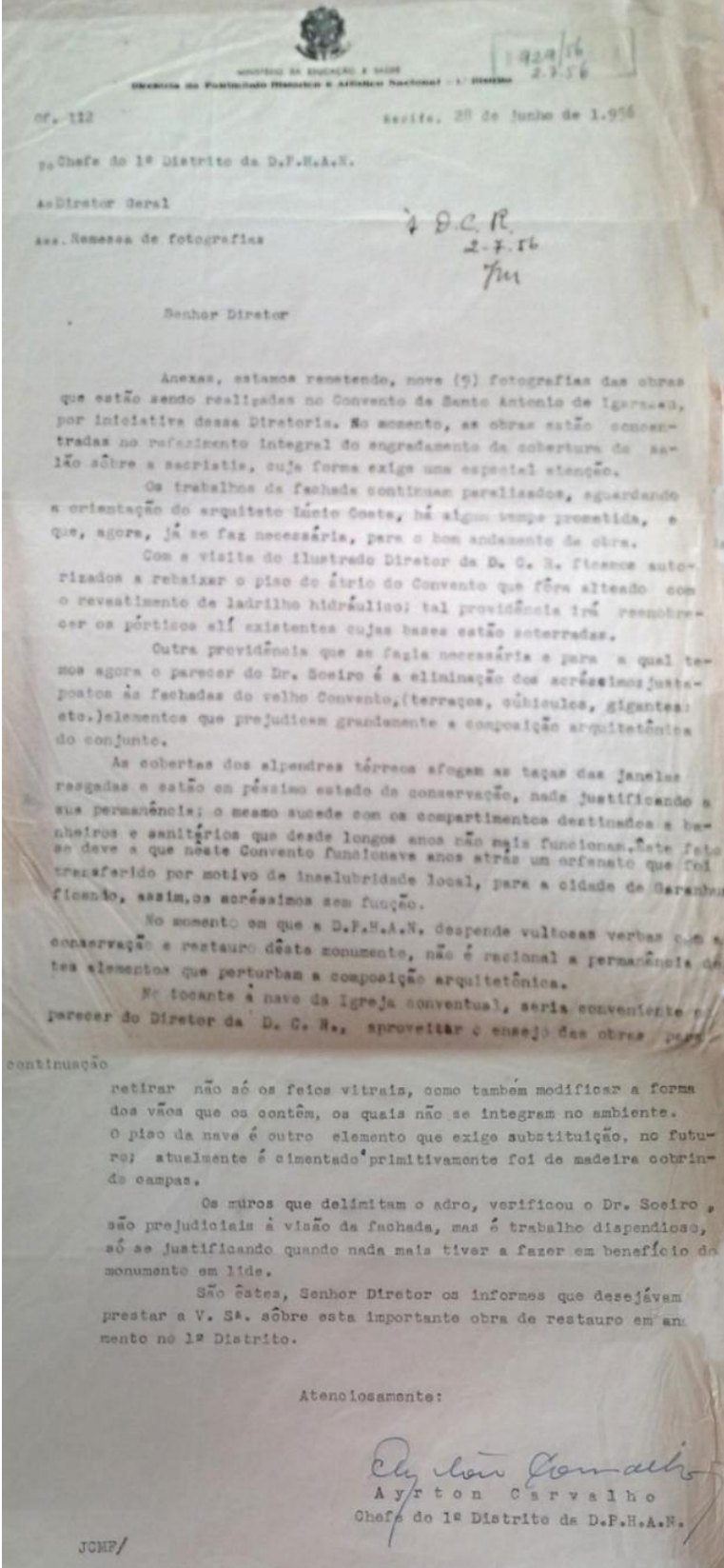

Figura 10: Ofício 112. Fonte: Pasta Série Obras, IPHAN/RJ 
Ana Maria Moraes Guzzo

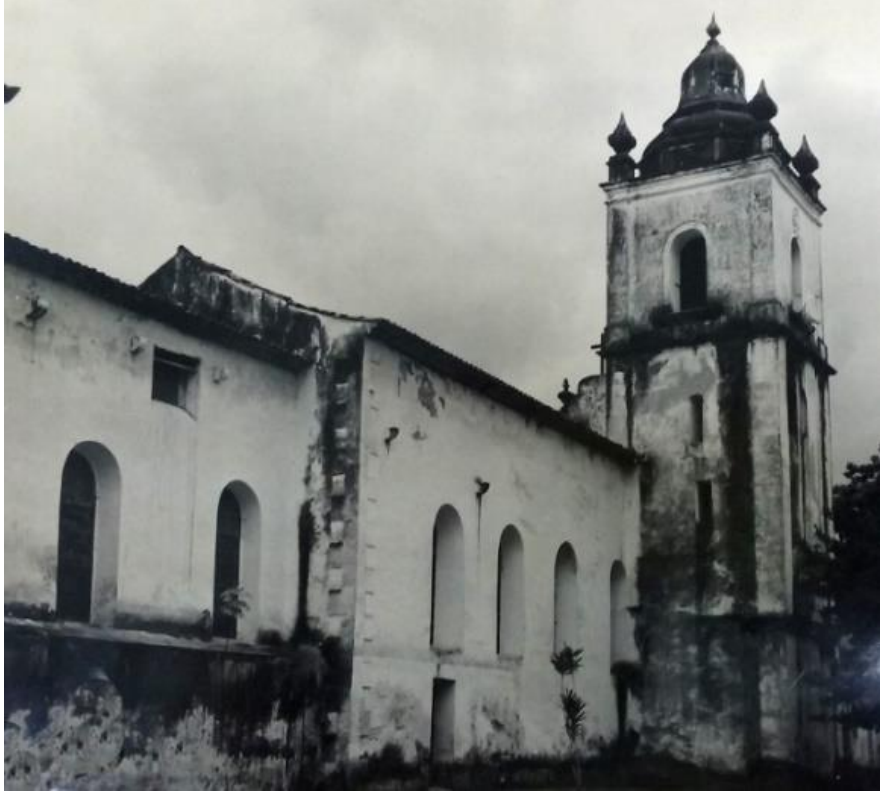

Figura 11: Fachada lateral esquerda, década de 1950. Vãos, antes de serem transformados em seteiras. "Óculo" quadrado. Fonte: DPHAN/Recife - 10, 34.03(5); 222.3; 316/58. Foto Gautherot

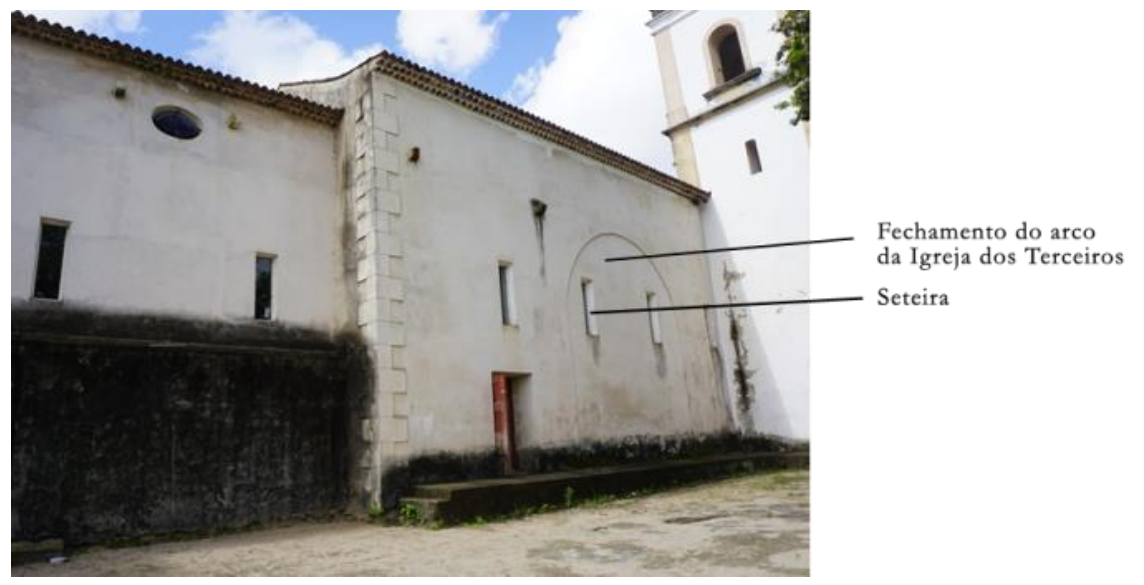

Figura 12: Fachada lateral esquerda, capela-mor e fechamento da Igreja dos Terceiros. Seteiras no lugar dos arcos e óculo modificado para oval, em julho de 1957. Fonte: Arquivo pessoal da autora, 2015
Um estudo sobre a evolução cronológica e intervenções realizadas no convento de lgarassu.

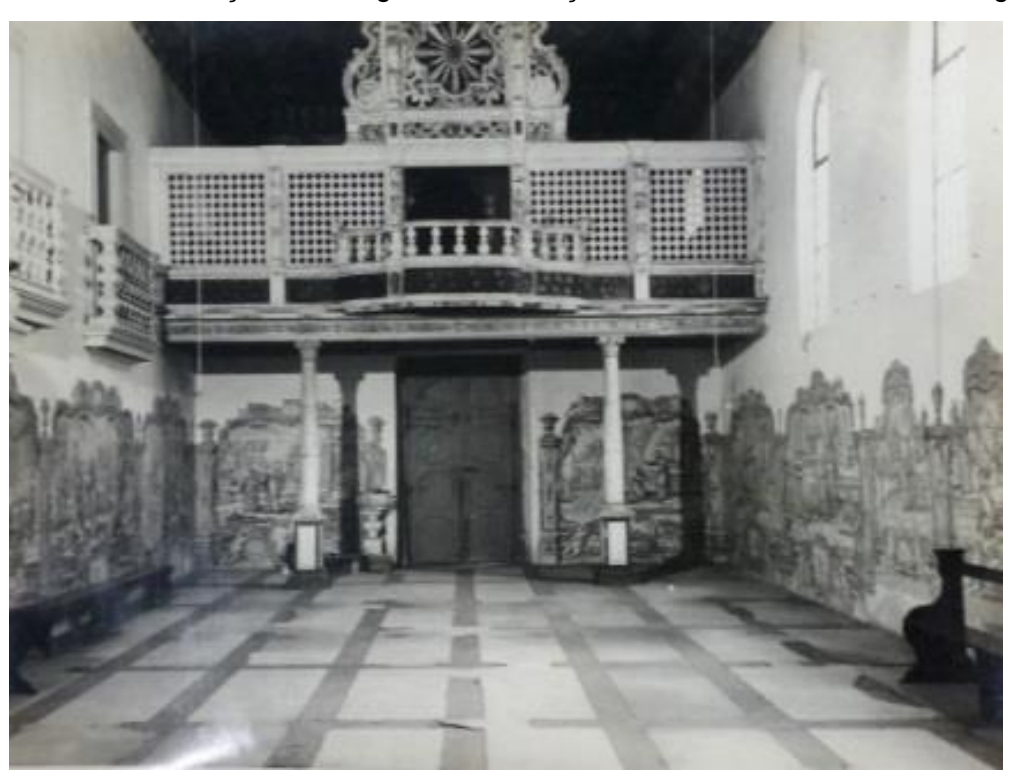

Figura 13: Vista do coro, vãos, azulejos cobrindo o arco de comunicação com a Ordem Terceira, e assoalho que era primitivamente em madeira e em 1956 estava cimentados. Fonte: IPHAN/PE, Pasta 34.03 (5); 222.57. Foto Campiglia

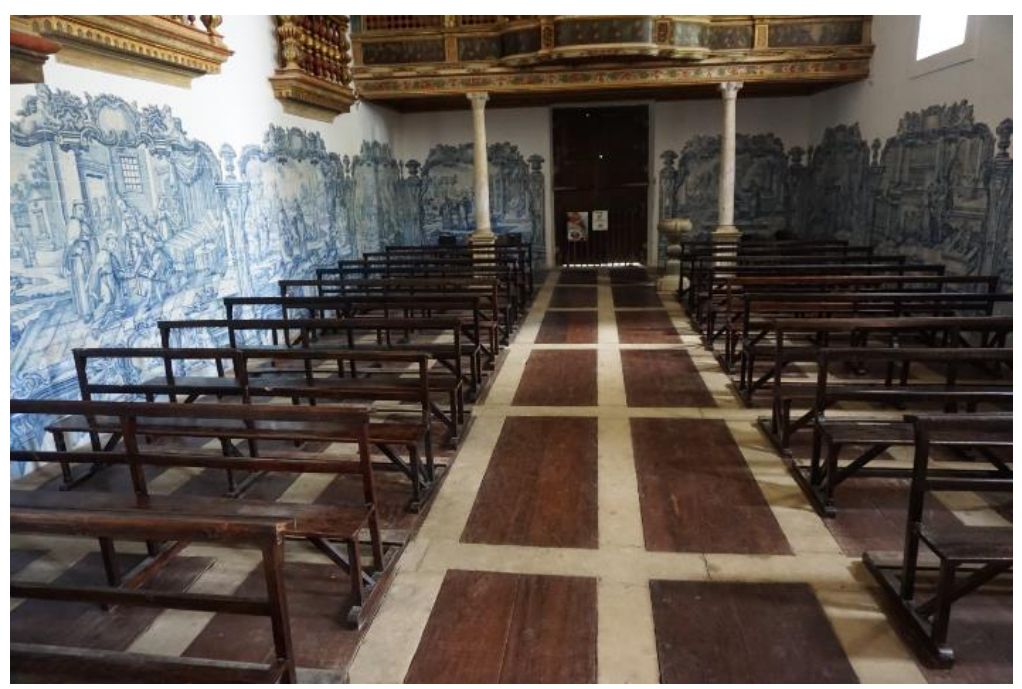

Figura 14: Piso da nave da Igreja. Fonte: Arquivo pessoal da autora, 2015 
A figura a seguir (figura 15) embora retratada em época recente, continua a mostrar as mudanças feitas no Convento.

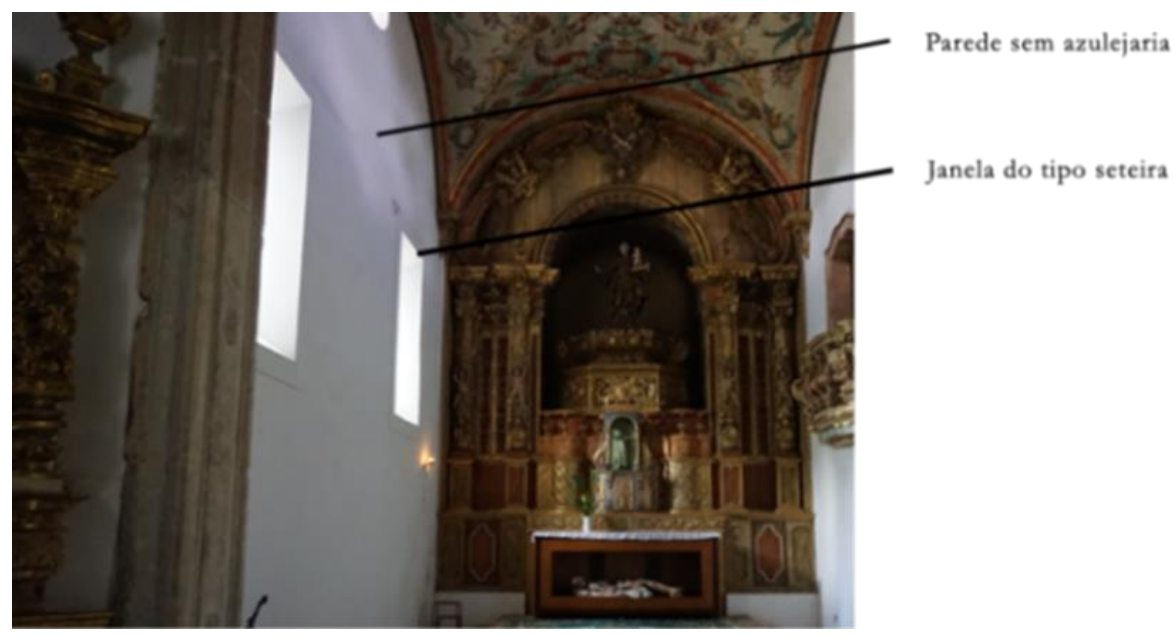

Figura 15: Parede da capela-mor sem a azulejaria, colocada no fechamento do arco de comunicação com a Ordem Terceira, no século XX. Janelas tipo seteira. Fonte: Arquivo pessoal da autora, 2015.

Em relação aos acréscimos já citados, optou-se pela demolição dos mesmos, gerando polêmica (Figuras 16).

Caminhando no tempo, a configuração do Convento de Igarassu chegou às feições a seguir que, ainda podem sofrer mudanças conforme intervenções vindouras (figura 17). Contudo, podemos observar que pouco mudou em sua "vida física".

O que hoje conhecemos desse convento é resultado das obras e adaptações descritas. Vale salientar que a literatura, as referências iconográficas e textuais acerca dessas obras presentes nos arquivos do IPHAN são escassas e apresentam lacunas. Um exemplo disso é a carência de documentação das intervenções realizadas no cenóbio, mesmo após o tombamento da edificação.
Um estudo sobre a evolução cronológica e intervenções realizadas no convento de lgarassu.

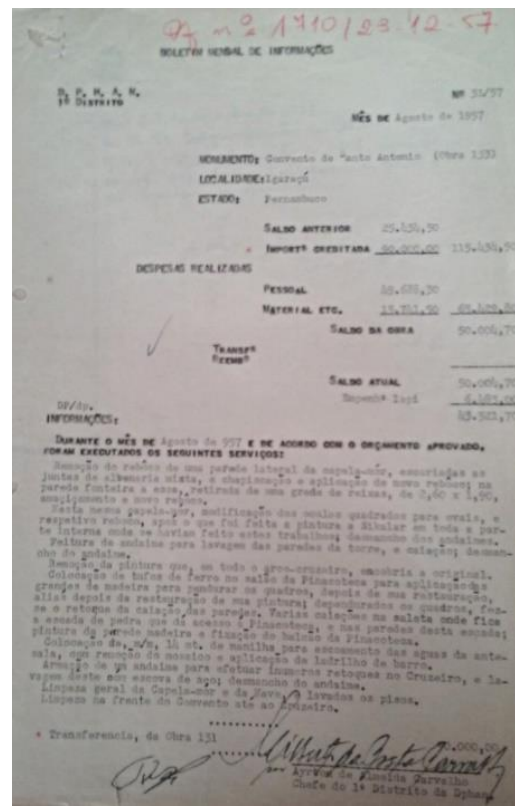

Figura 16: Boletim Mensal de Informações 31/57. Fonte: Pasta Série Obras, IPHAN/RJ

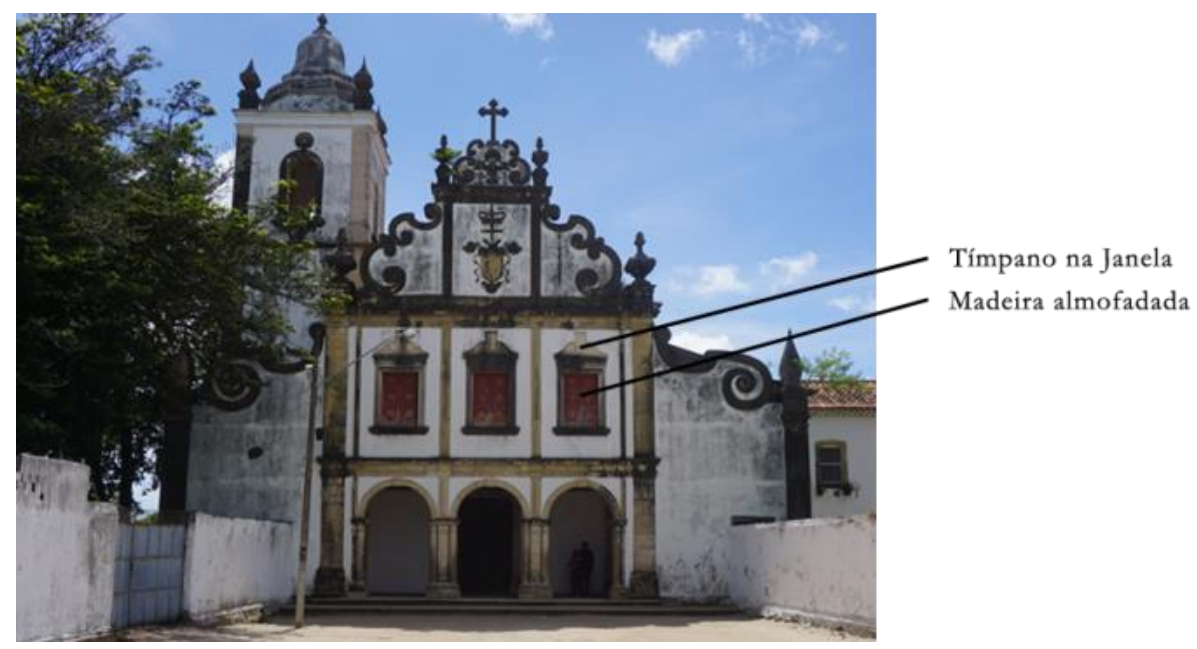

Figura 17: Fachada Principal e Cruzeiro. A modificação evidente é a presença de tímpanos nas janelas, talvez proveniente da restauração de 1999 feita em parceria com as Fundações citadas. Fonte: Arquivo pessoal da autora, 2015 


\section{Pós-operatório e Análises clínicas}

Por época da criação do IPHAN o Convento de Igarassu já havia sofrido várias intervenções. Um bom exemplo é o preenchimento com os azulejos retirados da capela-mor para cobrir, na parte interna, o arco entaipado de comunicação entre as igrejas dos Terceiros e a conventual.

$\mathrm{Na}$ obra de 1955, ao se extirpar as raízes existentes no frontão, viu-se que havia tímpanos nas janelas, com volutas e elementos esculpidos. A decisão foi manter as janelas sem os tímpanos. No entanto, na restauração feita em parceria pelas fundações portuguesa, espanhola e brasileira entre 1996 e 1998, os tímpanos foram novamente recolocados.

Ainda nessa ocasião, ao observar-se que o piso do átrio estava alteado com o revestimento assentado, optou-se por rebaixá-lo a fim de liberar os pórticos, cujas bases estavam soterradas. Houve relato de que as esquadrias envidraçadas que ocultavam as almofadas de madeira, originais, foram removidas, assim como os gradis de ferro da galilé.

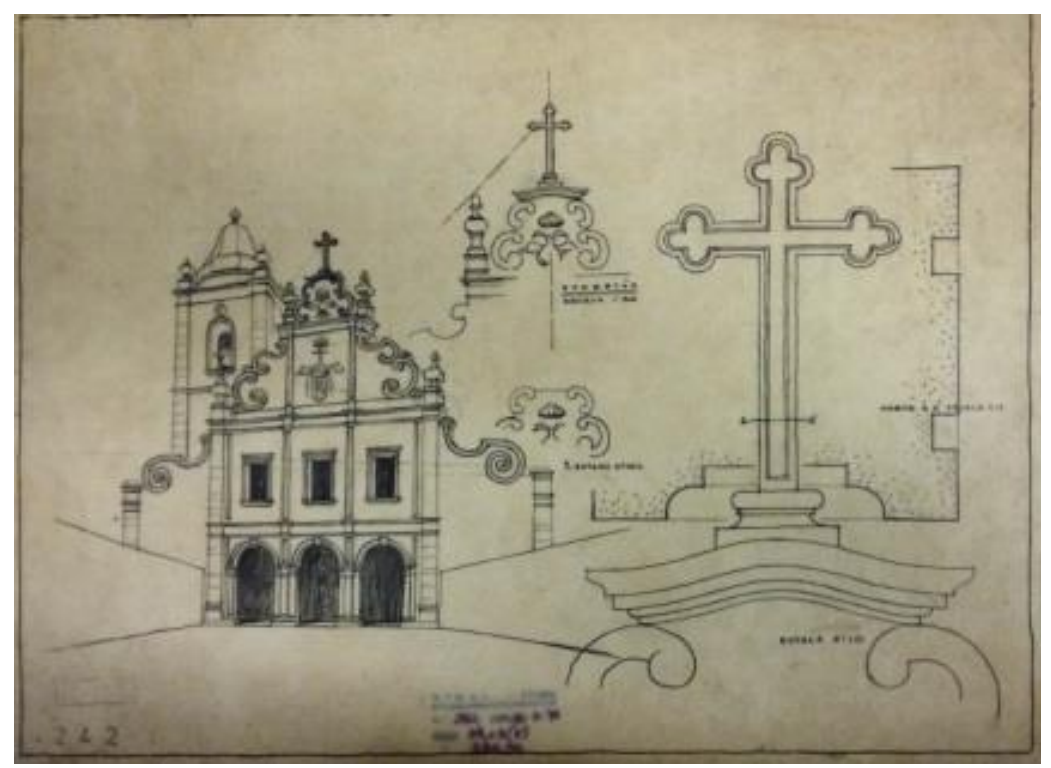

Figuras 18: Fachada desenhada em 1956. DPHAN/PE, Classificação 34.03 (5), registros 242.
Um estudo sobre a evolução cronológica e intervenções realizadas no convento de Igarassu.

Outra intervenção foi a realizada na fachada lateral esquerda (1957), em relação aos vãos que pareciam ter sido feitos em ocasião posterior à construção do convento. Seteiras os substituíram e o "óculo" quadrado transformou-se em oval.

Os pináculos que ladeavam o tímpano do frontispício, primitivamente feitos de cantaria, conviviam com os intermediários e os inferiores, confeccionados em massa, de épocas mais recentes. A cruz de cantaria do frontispício havia desaparecido, e outra de madeira ocupava seu lugar. Tanto os pináculos, quanto a cruz foram refeitos em cantaria (1957), mediante estudo (1956) (figuras 18 e 19).

Ao analisarmos as intervenções que ocorreram ao longo da existência do Convento salientamos que até a década de 1960 o campo disciplinar teórico da restauração não havia sido plenamente instituído no Brasil. As ações, de modo geral, eram guiadas pelo bom senso e calcadas em exemplos estrangeiros. Atualmente, as discussões conceituais continuam em debates, sendo a Teoria da Restauração de Cesare Brandi (2000), uma das mais aceitas, considerada como continuidade, consolidação e alargamento conceitual do chamado "restauro crítico" (tendência desenvolvida por Renato Botelli e Roberto Pane em meados do século XX), apresentando ainda convergências com posições defendidas precedentemente por teóricos como, Camillo Boito (2016) e Gustavo Giovannoni (2013), no que tange ao princípio da reversibilidade (recentemente enunciado como "retrabalhabilidade") e distinguibilidade, datando a restauração como fato histórico. As Cartas Patrimoniais/Cartas do Restauro foram importantíssimas nas recomendações a serem tomadas como base.

Para Brandi, o restauro era um ato crítico baseado no reconhecimento da obra de arte, que ultrapassava a instância histórica e estética; em relação às obras de arte, o restauro deveria apenas privilegiar a instância estética; o restauro é encarado como intervenção sobre a matéria e, assim, deverão ser salvaguardadas as ambiências e a espacialidade da obra como um todo. Brandi defendia as documentações históricas atreladas a um "juízo de valor". Quanto ao "refazimento", dizia que, o fato de se utilizar em um restauro o mesmo componente material da peça original, não significava que a matéria seria a mesma, sendo esta apenas historicizada, constituindo um falso histórico e estético. Assim, a intervenção precisava seguir sempre reconhecível, porém, sem afetar a própria unidade que se objetiva reconstruir. 


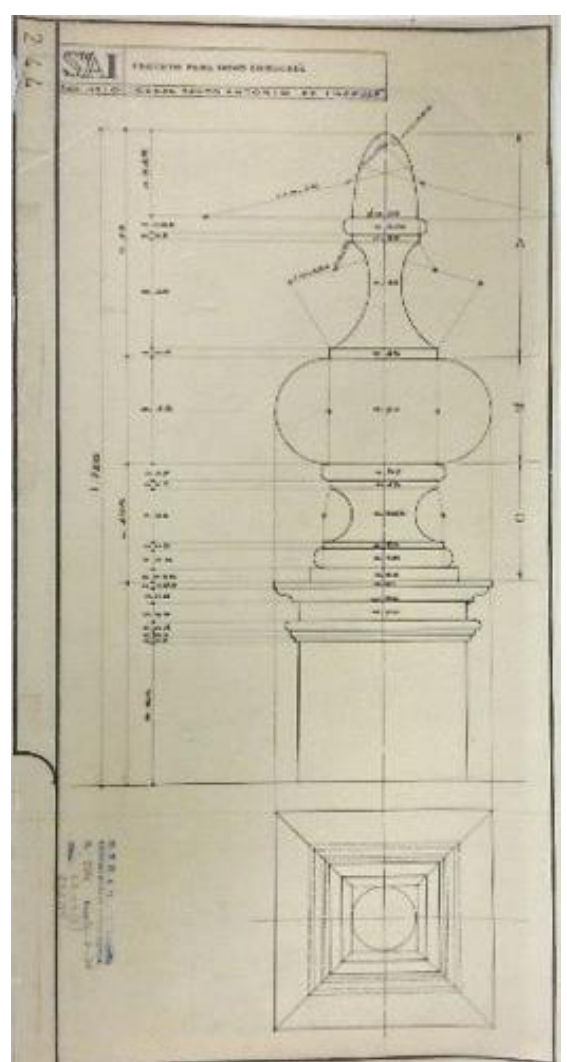

Figura 19: Projeto para novo pináculo, 1956. DPHAN, Classificação 34.03 (5), registro 244.

Acrescente-se ainda que, em qualquer intervenção, pelos princípios do teórico, as ações futuras deveriam ser facilitadas - princípio da reversibilidade (CARBONARA, 2006).

No Convento de Igarassu, as principais intervenções ocorreram anteriores aos conceitos citados. Os profissionais brasileiros se utilizavam de documentos do passado para basear suas ações. Os caminhos seguidos dependiam dos técnicos, mas não eram padronizados, terminando, por vezes, em ações confrontantes (CUNHA, 2010). Assim, ficaram à mostra contradições e adaptação de conceitos "estrangeiros" à nossa realidade, diante da inexperiência por parte dos "restauradores" no país.
Um estudo sobre a evolução cronológica e intervenções realizadas no convento de Igarassu.

Com base nisso, pode-se considerar, por exemplo, que a operação de retirada dos azulejos da capela-mor, bem como a prática de refazer elementos de acordo com os modelos "originais", indicam a prevalência do que seria a instância estética de Brandi (2000) empregada como justificativa teórica para a unidade estilística da obra. Isso era comum entre os teóricos do Patrimônio, e ainda ocorre, seguindo em parte os passos de Viollet-le-Duc (2006), tal como no exemplo citado da confecção dos pináculos e da cruz em cantaria. Para este estudioso, o monumento era considerado um documento que ilustrava um período da história, e as modificações feitas em épocas subsequentes não eram levadas em conta. Eliminavam-se alterações posteriores para devolver-lhe o aspecto de sua época de maior esplendor, às vezes reconstituído por analogia, ou, até mesmo, inventado, para se atingir um modelo ideal que pode nunca ter existido (KÜHL,1998). Apesar de Viollet-le-Duc ter sido duramente criticado, muitos de seus ensinamentos ainda são válidos, tais como: manter as estruturas originais (aparência e funcionamento); a importância do estudo de caso por caso; os trabalhos deveriam ser feitos com base em dados concretos.

O fato de os tímpanos serem novamente recolocados não impede a reversibilidade defendida por Brandi, Camillo Boito e Gustavo Giovannoni. O mesmo raciocínio segue quanto à retirada das esquadrias envidraçadas que ocultavam as almofadas de madeira, originais, assim como os gradis de ferro da galilé.

\section{Conclusão}

A preservação e a restauração ganharam importância no Brasil com a fundação do IPHAN, em 1937. Nessa ocasião foi necessário identificar os bens considerados de excepcional valor para nossa cultura, dedicar-lhes a proteção legal a partir dos processos de tombamento e executar as obras de restauração e conservação visando sua preservação.

A opção a ser tomada em uma intervenção deve contar com o embasamento conceitual teórico e posicionamento do profissional, além do conhecimento do objeto a ser preservado. O conhecimento das intervenções prévias, assim como o contexto no qual foram efetuadas, contribuem para a construção da História da Arte e Arquitetura no Brasil e futuras intervenções.

No caso do Convento de Igarassu após ao tombamento, podem ser observadas ações orientadas por diferentes posturas de restauração. Entretanto, constatamos 
que, apesar de a edificação ter perdido a função de convento, o bem foi preservado sem que houvesse apagamento da sua memória coletiva. As intervenções levaram à restituição da imagem do Convento em seu estado pleno. Outrossim, se considerarmos o período em que ocorreram obras no convento sob o comando do IPHAN e o momento atual, o monumento pouco se modificou. $O$ fato de no prédio haver se instalado uma pinacoteca, ampliou seu uso, sendo uma contribuição para sua preservação e permanência na memória coletiva.

Com efeito, o Convento pode ser considerado um caso relevante de estudo em que podem ser identificados erros e acertos. Acertos, no sentido de mantê-lo conservado, independente da mudança de seu uso. Erros, pela falta de registros das ações tomadas. Em face disso, tornamos a ressaltar a importância dos registros para que possamos construir e narrar uma história, mesmo diante de seu dinamismo e mutação.

\section{Referências}

BAZIN, Germain. A arquitetura religiosa barroca no Brasil. Tradução de Glória Lúcia Nunes. Rio de Janeiro: Record, 1983, 2v.

BELO, Albertina Marques Pires. As ordens terceiras de São Francisco na Zona da Mata: implantação da Província Franciscana de Santo Antônio do Brasil ao longo dos séculos XVII e XVIII. Tese (Doutoramento em História) - Faculdade de Ciências Humanas/Universidade Lusíada de Lisboa, Lisboa, 2013, 3 v.

BOITO, Camillo. Os Restauradores. Tradução de Beatriz Mugayar Kühl. São Paulo: Ateliê Editorial, 2016.

\section{BRANDI, Cesare. Teoria del Restauro. Editora Enaudi, 2000.}

CARBONARA, Giovanni. Brandi e a restauração arquitetônica hoje. Tradução de Beatriz Mugayar Kühl. Desígnio, 2006, n. 6, p. 35-47.

CUNHA, Cláudia dos Reis e. Restauração: diálogos entre teoria e prática no Brasil nas experiências do IPHAN. São Paulo, 2010.

FONSECA, Maria Cecília Londres. O Patrimônio em Processo: trajetória da política federal de preservação no Brasil. Rio de Janeiro; UFRJ: IPHAN:1997.
Um estudo sobre a evolução cronológica e intervenções realizadas no convento de Igarassu. GIOVANNONI, Gustavo. Textos Escolhidos. Tradução de Renata Campello Cabral. São Paulo: Ateliê Editorial, 2013.

JABOATÃO, Frei Antônio de Santa Maria. Novo orbe seráfico brasílico ou Crônica dos frades menores da Província do Brasil. Typ. Brasiliense de Maximiano Gomes Ribeiro, Lisboa, 1858, 4v.

KÜHL, Beatriz Mugayar. A restauração de monumentos históricos na França após a Revolução Francesa e durante o século XIX: um período crucial para o amadurecimento teórico. Revista CPC, São Paulo, n. 3, p. 110-144, nov. 2006/abr.2007. Disponível em: <http://citrus.uspnet.usp.br/cpc/v1/imagem/conteudo revista conservacao arquivo pdf/n3 beatr.pdf $>$. Acesso em: 20/08/2019.

ROWER, Frei Basílio. Páginas da história franciscana no Brasil. Petrópolis/RJ: Vozes, Rio de Janeiro, 1941.

SILVA, Maria João Espírito Santo Bustorff. (coord.) Igreja de Santo António de Igarassu. Conservação e Restauro. Fundação Ricardo do Espírito Santo Silva. Lisboa: Fundação Ricardo do Espírito Santo Silva, 2000.

VIOLLET-LE-DUC, Eugène Emanuel. Restauração. Tradução de Beatriz Mugayar Kühl. São Paulo: Ateliê Editorial, 2006. 